Revista Brasileira de Farmacognosia Brazilian Journal of Pharmacognosy 22(5): 964-970, Sep./Oct. 2012

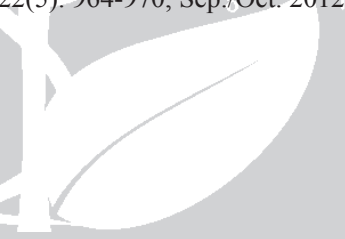

Article

Received 21 Nov 2011

Accepted 16 May 2012

Available online 6 Sep 2012

Keywords:

callus culture

HPLC

isoflavones

red clover

tetraploid Trifolium pratense

ISSN 0102-695X

http://dx.doi.org/10.1590/S0102 695X2012005000102

\section{In vitro isoflavonoid production and analysis in natural tetraploid Trifolium pratense (red clover) calluses}

\author{
Tugba Ercetin, ${ }^{1}$ Gulnur Toker, ${ }^{2}$ Murat Kartal, ${ }^{3}$ Hatice Colgecen,, 4 \\ Mehmet C. Toker
}

\author{
${ }^{1}$ Institute of Biotechnology, Ankara University, Turkey, \\ ${ }^{2}$ Department of Pharmacognosy, Faculty of Pharmacy, Turkey, \\ ${ }^{3}$ Department of Pharmacognosy, Faculty of Pharmacy, Ankara University, \\ Turkey, \\ ${ }^{4}$ Department of Biology, Faculty of Arts and Sciences, Zonguldak Karaelmas \\ University, Turkey, \\ ${ }^{5}$ Department of Biology, Faculty of Science, Ankara University, Turkey.
}

\begin{abstract}
Isoflavones are polyphenolic phytoestrogens, predominantly found in leguminous plants. Trifolium pratense L., Fabaceae (red clover), is rich in isoflavones that possess estrogenic activity due to their similar molecular structure and effectiveness in preventing health conditions such as menopause, osteoporosis, cardiovascular disease, hypertension and hormone-dependent cancers. In this study, presence and amount of various phytoestrogens in the tetraploid plant and in the calluses derived from the plants were investigated. Calluses were generated from explants obtained from natural tetraploid $T$. pratense seedlings. The best callus formation was obtained from hypocotyl explants cultured in Phillips Collins and Gamborg B5 media containing different plant growth regulators. Flowers of plants and calluses were analysed for formononetin, biochanin A, genistein and daidzein contents using HPLC. In HPLC analysis, high levels of formononetin $(0.249 \mu \mathrm{g} / \mathrm{mg})$ were determined in natural tetraploid $T$. pratense flowers in addition to genistein and biochanin A. In calluses, highest isoflavone content $(1.15 \mu \mathrm{g} / \mathrm{mg}$ formononetin $)$ was observed in modified Gamborg B5 medium. Biochanin A content of calluses and the plant were found to be nearly the same. But formononetin and genistein contents of the calluses in this medium were found to be respectively 4.62 and 21.39 folds higher than the tetraploid plant.
\end{abstract}

\section{Introduction}

Trifolium pretense L. (red clover) belongs to the Fabaceae family. In addition to being a good fodder plant, it has medical importance because of its phytoestrogens (isoflavones) content (Cornwell et al., 2004; Dixon, 2004; Geller \& Studee 2006; Baber, 2010; Ramos et al., 2011). T. pratense is agricultured widely in Europe, North America and it grows naturally in Southeastern Europe and Anatolia. Three varieties of $T$. pratense grown in Turkey are diploid, however T. pratense var. pratense's type $\mathrm{E} 2$ which is collected by Elci (1982) in the vicinity of Erzurum, Tortum is determined as a natural tetraploid.

T. pratense were used against cancer, bronchitis, liver disease, burns and wounds, rheumatism, skin diseases, ulcers, eczema and psoriasis (Kledjus et al., 2001). In recent years, it is widely used in preparations, particularly in Europe and America. During menopause, herbal treatment is preferred instead of hormone therapy, since hormone replacement therapy possesses breast and uterine cancer risk (Davis 2001; Djuric et al., 2001; Lu et al., 2001; Ganry, 2002; van de Weijer \& Barentsen, 2002; Mishra et al., 2003; Arjmandi et al., 2003, Magee \& Rowland, 2004; Beck et al., 2005; Howes et al., 2006). Although, primary effects are seen on pre and post-menopausal symptoms, it is also used for prevention of cardiovascular disease and osteoporosis, and regulation of blood lipid profile (Lissin \& Cooke, 2000; Cesar et al., 2006; Smiley \& Khalil, 2009). In diploid T. pratense callus and suspension culture, plant regeneration attempts have been investigated by various researchers (Phillips \& Collins, 1979; Wang \& Holl, 1988; Kasparova et al., 2006). For the tetraploid form, a few studies related to its anatomy (Algan \& Bakar, 1999) and morphology (Pinar et al., 2001) have 
been realized. In vitro plant regeneration in natural tetraploid $T$. pratense has been done by Colgecen and Toker (2008). However, various isoflavone analysis studies were made on the diploid T. pratense (Kledjus et al., 2001; Krenn et al., 2002; Wu et al., 2003; Delmonte et al., 2006) and other Fabaceae species (Kennely et al., 2002; Wang et al., 2002; Kledjus et al., 2004; Kledjus et al., 2005; Jiang et al., 2006; Kledjus et al., 2008). such a study was not done in the natural tetraploid form. The present research was undertaken to identify and quantify some of the isoflavones in the tetraploid red clover flowers and in the calluses derived from them. In addition, a reproducible method for callus production from in vitro germinated seedlings of natural tetraploid T. pratense with various media and growth regulators was investigated.

\section{Materials and Methods}

\section{Plant material}

In this study, E2 type natural tetraploid Trifolium pratense L., Fabaceae, $2 \mathrm{n}=4 \mathrm{x}=28$ chromosomes collected by Elci (1982) from the vicinity of Erzurum, Tortum, Turkey were used. The natural tetraploid $T$. pratense $\mathrm{L}$. is a superior form in terms of its diploid varieties. The natural tetraploid T. pratense L. E2 type was grown in the experimentation gardens of Ankara University, Department of Biology and Faculty of Science. We used seeds and flowers which are official parts of the plants.

\section{Callus cultures}

Seeds were first sterilized in $96 \%$ ethanol for one minute and then transferred to $10 \%$ chlorine bleach solution for $10 \mathrm{~min}$ (commercial sodium hypochlorite was used in the sterilization process). Then seeds were rinsed three times in autoclaved distilled water. After being scarified with autoclaved sandpaper, seeds were germinated in hormone free Murashige and Skoog media (MS) (Murashige \& Skoog, 1962). Fifteen day old aseptic seedlings were used as the explant source. $1 \mathrm{~cm}$ long hypocotyl explants were cultured in MS, Phillips and Collins (PC-L2) (Phillips \& Collins, 1979), Gamborg B5 (B5) (Gamborg et al., 1976) media supplemented with different hormone combinations, $2 \%$ sucrose and $0.8 \%$ agar. Benzylaminopurine (BAP) (2.2 $\mu \mathrm{M})$, naphthaleneacetic acid (NAA) (P1) (27 $\mu \mathrm{M}) ; 8.9 \mu \mathrm{M}$ BAP, $5.4 \mu \mathrm{M}$ NAA (P2); $0.27 \mu \mathrm{M}$ 2,4dichlorophenoxyacetic acid (2,4-D), $0.16 \mu \mathrm{M}$ NAA, $0.44 \mu \mathrm{M}$ BAP (P3) and $0.27 \mu \mathrm{M} 2,4-\mathrm{D}, 0.44 \mu \mathrm{M}$ BAP (P4) were used in PC-L2 and MS media and 11 $\mu \mathrm{M}$ NAA, $10 \mu \mathrm{M}$ 2,4-D $10 \mu \mathrm{M}$ Kinetin (KIN) in B5 medium as plant growth regulators. All media had been adjusted to $\mathrm{pH} 5.8$ and autoclaved for $20 \mathrm{~min}$ at $121{ }^{\circ} \mathrm{C}$. Calluses were sub-cultured in the same medium, every 26-28 days. All experiments were repeated three times. The cultures were incubated at photo-period of $16 / 8 \mathrm{~h}$ and the temperature has been set to $25 \pm 1{ }^{\circ} \mathrm{C}$ (irradiation with $42 \mu \mathrm{mol} \mathrm{m}^{-2} \mathrm{~s}^{-1}$ provided by cool-white fluorescent tubes). Callus growth index were used in determining the callus production in media containing different growth regulators (Table 1) (Callus growth index $(\mathrm{GI})=$ final weight/initial weight).

\section{Extraction and analysis of isoflavones}

Natural tetraploid T. pratense dried flowers and second and third subculture calluses were used in TLC and HPLC analysis. HPLC analysis was not performed from P4 medium because only a small amount of callus had been developed on this medium.

\section{Sample preparation}

Powdered air-dried flowers $(400 \mathrm{mg}$ ) and freeze-dried of hypocotyl calluses $(200 \mathrm{mg}$ ) were weighed and extracted with $5 \mathrm{~mL} 80 \%$ methanol and

Table 1. Callus growth index of natural tetraploid Trifolium pratense calluses on PC-L2 and B5 media. ANOVA statistical analysis $(p \leq 0.05)$ was performed (mean $\pm \mathrm{SE})$.

\begin{tabular}{|c|c|c|c|c|c|}
\hline Type of growth medium & Growth regulators $(\mu \mathrm{M})$ & Callus & Subculture 1. & Subculture 2. & Subculture 3 \\
\hline $\mathrm{P} 1$ & $\begin{array}{l}\text { 2.2 BAP } \\
\text { 27 NAA }\end{array}$ & $80 \pm 1.021^{\mathrm{b}}$ & $6,85 \pm 0,043^{\mathrm{b}}$ & $1,58 \pm 0,013^{\mathrm{b}}$ & $1,31 \pm 0,001^{\mathrm{ab}}$ \\
\hline $\mathrm{P} 2$ & $\begin{array}{l}\text { 8.9 BAP } \\
\text { 5.4 NAA }\end{array}$ & $35 \pm 0,085^{\mathrm{a}}$ & $3,57 \pm 0,064^{\mathrm{a}}$ & $1,92 \pm 0,019^{\mathrm{a}}$ & $1,27 \pm 0,001^{\mathrm{ab}}$ \\
\hline P3 & $\begin{array}{c}0.27 \text { 2,4-D } \\
0.16 \text { NAA } \\
0.44 \text { BAP }\end{array}$ & $50 \pm 0,956^{\mathrm{a}}$ & $4,2 \pm 0,643^{\mathrm{a}}$ & $3.0 \pm 0,405^{\mathrm{a}}$ & $1,29 \pm 0,033^{\mathrm{ab}}$ \\
\hline P4 & $\begin{array}{c}0.27 \text { 2,4-D } \\
0.44 \text { BAP }\end{array}$ & $41 \pm 0,982^{\mathrm{a}}$ & $3,29 \pm 0,205^{\mathrm{a}}$ & $1,89 \pm 0,001^{\mathrm{a}}$ & $1,96 \pm 0,001^{\mathrm{a}}$ \\
\hline B5 & $\begin{array}{c}11 \text { NAA } \\
10 \text { 2,4-D } \\
10 \mathrm{KIN}\end{array}$ & $55 \pm 1,017$ & $7,91 \pm 0,484$ & $1,41 \pm 0,064$ & $1,14 \pm 0,065$ \\
\hline
\end{tabular}


$1 \mathrm{~mL} 2 \mathrm{M} \mathrm{HCl}$. Samples were kept in an ultrasonic bath for $10 \mathrm{~min}$ after $80{ }^{\circ} \mathrm{C}$ water bath $80 \mathrm{~min}$. After filtration samples were adjusted to a standard volume of $10 \mathrm{~mL}$ with $80 \%$ methanol.

\section{TLC analysis}

Samples were analyzed by TLC for their isoflavone content, before the HPLC analysis. TLC was carried out on Kieselgel 60 F254 (precoated, $0.2 \mathrm{~mm}$ thick plastic plates, Merck) by using mobile systems; chloroform-acetone-formic acid (75:16.5:8.5) (S1) and chloroform-ethyl acetate (1:1) (S2). Isoflavones were detected under $\mathrm{UV}_{366}$ and upon plates being exposed to the ammonia vapour, colors were intensified. Isoflavones were seen with their specific colors under $\mathrm{UV}_{366}$.

\section{HPLC analysis}

\section{Reagents and chemicals}

Formononetin (Fluka-47752, USA), biochanin A (Fluka-14385, Germany), genistein (Fluka-91955, China) and daidzein (Sigma-D7802, Germany) were obtained as reference compounds. Chromatographic grade-double distilled water; HPLC grade methanol (Merck-34885) and analytical grade acetonitrile (Merck-34998) were used.

\section{Apparatus}

Modified method was performed with a LC system consisting of a HP Agilent 1100 series Quaternary pump with degasser and photodiode array detector. Samples were injected with HP Agilent 1100 Auto samplers with thermostat controlled column compartment on a Lichrospher $100 \mathrm{RP}-18,5 \mu \mathrm{m}$ particle size column $(250 \mathrm{mmx} 4.6 \mathrm{~mm})$, at $30{ }^{\circ} \mathrm{C}$. The system was controlled and data analysis was performed with Agilent ChemStation. All the calculations concerning the quantitative analysis were performed with external standardization by measurement of the peak areas.

\section{Stock and standard solutions}

As a standard formononetin, biochanin A, daidzein and genistein were accurately weighed as $10 \mathrm{mg}$ and each were placed into a $10 \mathrm{~mL}$ volumetric flask, dissolved in the methanol:water (80:20) and were filled up to volume for preparing stock solutions. Standard solutions were prepared separately using same solvent combination for each isoflavones at six different concentration levels in $10 \mathrm{~mL}$ volumetric flasks. The stock solutions were serially diluted with the same solvent combination to make samples with concentrations of $1,10,15,20,30$ and $100 * \mathrm{~g} \mathrm{~mL}^{-1}$.

\section{Chromatographic conditions}

We modified the HPLC method developed by $\mathrm{Wu}$ et al. (2003). HPLC analysis was performed by gradient elution, with flow rate of $1.5 \mathrm{~mL} / \mathrm{min}$. The mobile phase was delivered from two separate containers with gradient elution program. The first container was $0.1 \%$ formic acid in water (solution A); the second container was $0.1 \%$ formic acid in acetonitrile (solution B). All solvents were filtered through a $0.45 * \mathrm{~m}$ Millipore filter before use and degassed in an ultrasonic bath. The separation solvent program consisted of $70 \% \mathrm{~A}$ and $30 \% \mathrm{~B}$ at $\mathrm{T}=0$ followed by gradient of $70 \%$ to $60 \%$ A over $30 \mathrm{~min}$ and $60 \%$ to $50 \%$ A over $10 \mathrm{~min} .10 * \mathrm{~L}$ of standards and samples were injected onto column and the chromatograms were recorded from 200 to $400 \mathrm{~nm}$. Quantification was effected by the measurement of isoflavones at $254 \mathrm{~nm}$, using photo-diode array detector. The chromatographic run time was $50 \mathrm{~min}$.

\section{Calibration}

Standard solutions containing formononetin (1.0-100 $\mu \mathrm{g} / \mathrm{mL})$, biochanin A $(1.0-100 \mu \mathrm{g} / \mathrm{mL})$, daidzein $1.0-100 \mu \mathrm{g} / \mathrm{mL})$, genistein $(1.0-100 \mu \mathrm{g} / \mathrm{mL})$ were prepared in the mobile phase. Triplicate $10 \mu \mathrm{L}$ injections were made for each standard solution to see the formation of the detector response at each concentration level. The peak area of each compound was plotted against the concentration to obtain the calibration graph. The six concentrations of each compound were subjected to regression analysis to calculate calibration equation and correlation coefficients.

\section{Linearity}

Table 2 presents the equation of the regression line, correlation coefficient $\left(\mathrm{r}^{2}\right)$, for each compound. Excellent linearity was obtained for compounds between peak areas and concentrations for formononetin, biochanin A, daidzein and genistein, respectively.

\section{Limits of Detection and Quantification}

Limits of detection (LOD) were established at a signal-to-noise ratio $(\mathrm{S} / \mathrm{N})$ of 3 . Limits of quantification (LOQ) were established at signal-to-noise ratio $(\mathrm{S} / \mathrm{N})$ of 10 . LOD and LOQ were experimentally verified by six injections of formononetin, biochanin A, daidzein and genistein at the LOD and LOQ concentrations. The LOD was calculated to be $0.03 \mu \mathrm{g} / \mathrm{mL}$; the LOQ was 
calculated to be $0.1 \mu \mathrm{g} / \mathrm{mL}$ for formononetin, biochanin A, daidzein and genistein (Table 2).

Table 2. Linearity results, Limit of Detection (LOD) and Limit of Quantification (LOQ), $\lambda 254 \mathrm{~nm}$.

\begin{tabular}{lcccc}
\hline & Equation & $\mathrm{r}^{2}$ & $\begin{array}{c}\mathrm{LOQ} \\
(\mu \mathrm{g} / \mathrm{mL})\end{array}$ & $\begin{array}{c}\mathrm{LOD} \\
(\mu \mathrm{g} / \mathrm{mL})\end{array}$ \\
\hline Formononetin & $\mathrm{Y}=45.2471 \mathrm{X}+33.0911$ & 0.9998 & 0.10 & 0.03 \\
Biochanin A & $\mathrm{Y}=58.6493 \mathrm{X}+1.3293$ & 0.9999 & 0.10 & 0.03 \\
Daidzein & $\mathrm{Y}=48.5306 \mathrm{X}+15.3230$ & 0.9997 & 0.10 & 0.03 \\
Genistein & $\mathrm{Y}=68.0299 \mathrm{X}+44.9278$ & 0.9997 & 0.10 & 0.03 \\
\hline
\end{tabular}

\section{Statistical analysis}

The data in Table 1 were subjected to oneway analysis of variance (ANOVA) and the differences among the means were compared by Duncan's multiplerange test (Duncan, 1955). B5 and PC-L2 media were compared using a paired Student's t-test. Each treatment was replicated three times and arranged in a completely randomized design. Parts of plants and flowers, $2^{\text {nd }}, 3^{\text {rd }}$ callus culture extracts was injected three times and the results were assessed according to the statistical program SPSS and standard error values were calculated.

\section{Results and Discussion}

Due to its better vegetative characteristics, natural tetraploid Trifolium pratense L., Fabaceae, is considered a superior forage plant compared to diploid form. T. pratense is also utilized as an ingredient in numerous homeopathic medicines; it has also been used to relieve menopausal complaints due to its function as a phytoestrogen and also has been used in cancer treatment due to its anti-tumoral properties (Brzezinski $\&$ Debi, 1999). The seeds were sown in hormone-free MS medium and after fifteen days became seedlings (Colgecen and Toker, 2008). These seedlings were used as explants source. In our experiment, in order to obtain the best callus formation MS, PC-L2 and B5 nutrient media with plant growth regulators which have been working in the Fabaceae family were used (Luczkiewicz \& Glod, 2003; Matkowski, 2004). PC-L2 media gave better results compared with the MS in the preliminary studies so MS media was not used in the ongoing studies. Callus formation began at sixth day on hypocotyl explants (about $1 \mathrm{~cm}$ long and 0.002-0.0025 g fresh weight) sown in these media. Developed calluses were transferred to the sub-cultures for three times in 26-28 day period. Dark yellow and white colored, soft mucous-like structured calluses in B5 medium were formed, while green, white, brown, dark and light yellow friable calluses formed in the other media (MS, PC-L2). A more rigid structure was seen in green colored calluses. In some calluses obtained from the first sub-culture, air-root formation was also observed in P1 media. According to the literature, PC-L2 and B5 media have been used for the callus production studies on Trifolium species. Phillips and Collins (1979) have used $0.25 \mu \mathrm{M}$ Picloram and $0.44 \mu \mathrm{M}$ BAP in callus and shoots production experiments. It has been reported that the decision of NAA addition to the media may be effective in the production of the phenolic and related compounds on calluses. In our study, $0.27 \mu \mathrm{M} 2,4-\mathrm{D}$, $0.44 \mu \mathrm{M}$ BAP (P4) and $0.27 \mu \mathrm{M} 2,4-\mathrm{D}, 0.16 \mu \mathrm{M}$ NAA, $0.44 \mu \mathrm{M}$ BAP (P3) containing PC-L2 media were used based on this information.

According to data we obtained herein, the best callus development was observed in P1 medium and it was followed by B5, P3, P4 and P2 media respectively (Table 1). Callus growth in callus and sub-cultures, were compared according to Duncan Test. While, callus, the first and the second sub-culture calluses of P2, P3 and P4 media were being similar, differences were observed in P1 medium. P4 medium callus was different in the third sub-culture than other PC-L2 media. B5 medium and $\mathrm{P} 1$ medium which were providing the best callus growth among PC-L2 media were compared with Student's t-test. Because the tscore value in callus is bigger than value $t_{\text {table }}$, significant differences were determined between the two media. In the first, second and third sub-culture calluses, because the value $t_{\text {score }}$ are smaller than value $t_{\text {table }}$, significant differences were not determined between the two media.

Beach \& Smith (1979) had used hypocotyls and ovaries as explant in plant regeneration studies from $T$. pratense and $T$. incarnatum and the best callus growth has been obtained from hypocotyl explants in B5 medium supplemented with $11 \mu \mathrm{M}$ NAA, 10 $\mu \mathrm{M} 2,4-\mathrm{D}$ and $10 \mu \mathrm{M}$ KIN hormone mixture in seven weeks. Kasparova et al., (2006) had studied callus and suspension culture in B5 medium supplemented with 2 $\mathrm{mg} \mathrm{L}^{-1} 2,4-\mathrm{D}$ and $2 \mathrm{mg} \mathrm{L}^{-1} \mathrm{BAP}$ in diploid $T$. pratense and calluses were transferred to the subcultures in 29-43 days. They have analyzed formononetin content with HPLC and TLC. In our study, also harvestable amounts of calluses were obtained from hypocotyl explants in 26-28 days in all media.

In TLC analysis of flower and callus extracts, with Kieselgel 60 F254 as adsorbent, chloroform-ethyl acetate (1:1) (S2) solvent system were used and good separation was obtained for isoflavones. $R_{f}$ values of daidzein, genistein, formononetin and biochanin $\mathrm{A}$ were determined as $0.37,0.51,0.54,0.63$, respectively in S2 solvent system. In our study, formononetin has been identified in tetraploid plant flowers while four isoflavones were found in calluses. Then, the HPLC results obtained later also confirmed these findings (Table 3). 
Table 3. Isoflavone amounts $(\mu \mathrm{g} / \mathrm{mg})$ of Trifolium pratense flowers and calluses.

\begin{tabular}{|c|c|c|c|c|c|c|}
\hline & Media & & & Isoflavones & & \\
\hline & Growth regulators $(\mu \mathrm{M})$ & Subcultures & Daidzein & Genistein & Formononetin & Biochanin A \\
\hline \multirow{2}{*}{ P1 } & 2.2 BAP & II. & $0.010 \pm 0.003$ & $0.058 \pm 0.6$ & $0.353 \pm 0.03$ & $0.044 \pm 0.61$ \\
\hline & 27 NAA & III & $0.009 \pm 0.006$ & $0.035 \pm 0.66$ & $0.457 \pm 0.45$ & $0.098 \pm 0.05$ \\
\hline \multirow{3}{*}{$\mathrm{P} 2$} & 8.9 BAP & II. & $0.013 \pm 0.01$ & $*$ & $0.245 \pm 0.02$ & $0.099 \pm 1,3$ \\
\hline & 5.4 NAA & III & $0.027 \pm 0.008$ & $0.085 \pm 0.7$ & $0.198 \pm 15$ & $0.046 \pm 0.5$ \\
\hline & $0.272,4-\mathrm{D}$ & II. & $*$ & $0.045 \pm 1.71$ & $0.111 \pm 0.5$ & $0.020 \pm 0.19$ \\
\hline \multirow[t]{3}{*}{ P3 } & $0.16 \mathrm{NAA}$ & & & & & \\
\hline & 0.44 BAP & III & $0.011 \pm 0.02$ & $0.021 \pm 0.21$ & $0.220 \pm 0.08$ & $0.015 \pm 0.6$ \\
\hline & 11 NAA & & & & & \\
\hline \multirow[t]{3}{*}{ B5 } & $102,4-\mathrm{D}$ & II. & $0.003 \pm 0.1$ & $0.232 \pm 0.3$ & $1.148 \pm 0.4$ & $0.083 \pm 0.22$ \\
\hline & $10 \mathrm{KIN}$ & III & $0.002 \pm 0.006$ & $0.426 \pm 0.25$ & $0.327 \pm 0.18$ & $0.071 \pm 0.03$ \\
\hline & Tetraploid flower & & - & $0.020 \pm 0.55$ & $0.2485 \pm 0.7$ & $0.072 \pm 0.1$ \\
\hline
\end{tabular}

* Trace; - Peak was not observed.

Retention times for daidzein, genistein, formononetin and biochanin A were observed to be 9-10, 17-18, 24-25, 39-40 min, respectively in HPLC analysis (Figure 1). Formononetin was detected as the main component, while genistein, biochanin A were detected in lesser concentration in tetraploid flowers. High amount of formononetin $(0.249 \mu \mathrm{g} / \mathrm{mg})$ and various amounts of other isoflavones were determined in the plant flowers (Figure 2). The highest amount of formononetin $(1.15 \mu \mathrm{g} / \mathrm{mg})$ was determined in B5 medium in the second sub-culture calluses (Figure 3). However, the amount of substances were decreased in the third sub-culture in most of calluses, formononetin amount has been increased in P1, P3 and genistein in B5 in third sub-culture $(0.426 \mu \mathrm{g} / \mathrm{mg})$ compared with the second sub-culture $(0.232 \mu \mathrm{g} / \mathrm{mg})$. The sharp decline was determined to third sub-culture in the B5 medium for amount of formononetin ( from $1.15 \mu \mathrm{g} / \mathrm{mg}$ to 0.327 $\mu \mathrm{g} / \mathrm{mg}$ ) (Table 3).

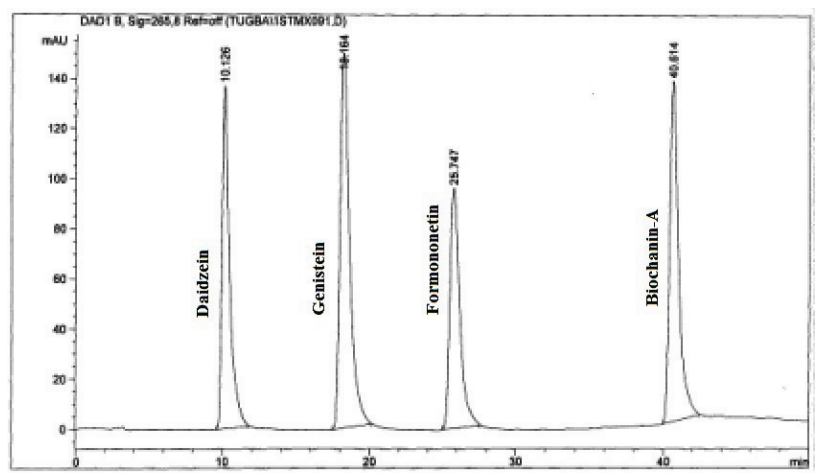

Figure 1. Chromatogram of the mixture of daidzein (10.126 $\mathrm{min})$, genistein (18.164 $\mathrm{min})$, formononetin $(25.747 \mathrm{~min})$ and biochanin A (40.614 min) at $254 \mathrm{~nm}$ by modified HPLC method.

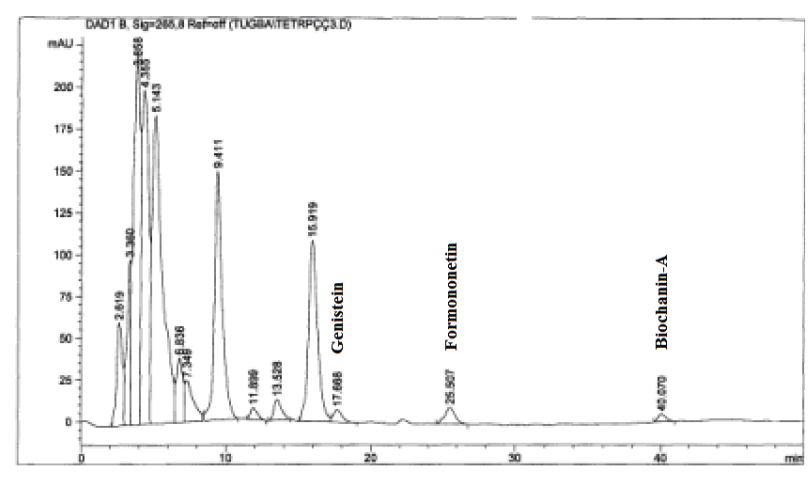

Figure 2. HPLC chromatogram of on tetraploid Trifolium pratense flower.

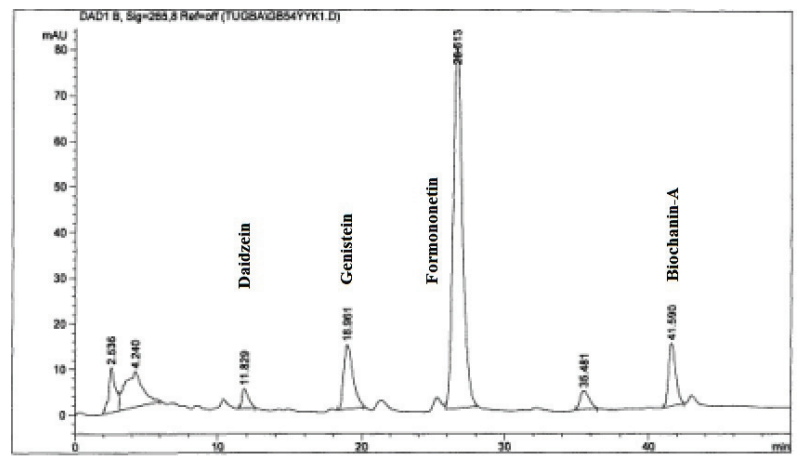

Figure 3. HPLC chromatogram of the second sub-culture on B5 medium callus.

Krenn et al., (2002) and Wu et al., (2003) worked on HPLC separation of isoflavones in $T$. pretense, previously. Krenn et al., (2002) have found that the amounts of formononetin $(2.65-2.89 \mu \mathrm{g} / \mathrm{mg})$ and biochanin A (1.89-2.04 $\mu \mathrm{g} / \mathrm{mg})$ were higher than the amounts of genistein $(0.07-0.1 \mu \mathrm{g} / \mathrm{mg})$ and daidzein $(0.10-0.11 \mu \mathrm{g} / \mathrm{mg})$ in plant extracts. Wu et al., (2003) 
have determined that formononetin $(0.18-0.38 \mu \mathrm{g} / \mathrm{mg})$, genistein $(0.06-0.13 \mu \mathrm{g} / \mathrm{mg})$, daidzein $(0.04-0.05 \mu \mathrm{g} /$ $\mathrm{mg})$ and biochanin A $(0.09-1.66 \mu \mathrm{g} / \mathrm{mg})$ in the plant flower extracts. Generally, our findings were higher than the findings of $\mathrm{Wu}$ et al. while lower than that the findings of Krenn et al. (2002).

In conclusion, the best callus formation was observed in P1 medium and B5, P3, P4 and P2 media respectively. The calluses were good in quality and also applicable for suspension cultures. In HPLC, high levels of formononetin $(0.249 \mu \mathrm{g} / \mathrm{mg})$ were determined in natural tetraploid $T$. pratense flowers in addition to genistein and biochanin A. In calluses, the highest formononetin content $(1.15 \mu \mathrm{g} / \mathrm{mg}$ formononetin) was observed in B5 medium supplemented with $11 \mu \mathrm{M}$ NAA, $10 \mu \mathrm{M} 2,4-\mathrm{D}$ and $10 \mu \mathrm{M}$ kinetin. However, biochanin $\mathrm{A}$ content in calluses and the plant was found similar, the formononetin and genistein contents were found to be 4.62 and 21.39 folds higher than the ones in tetraploid flowers. To the best of our knowledge, we herein report in vitro isoflavonoid production and analyses on natural tetraploid $T$. pratense for the first time. Our findings will be basis for future biotechnological studies on natural tetraploid Trifolium pretense as a phytoestrogen source.

\section{References}

Algan G, Bakar HN 1999. Apomictic development in tetraploid Red Clover (Trifolium pratense L.). Turk $J$ Agric For 23: 519-526.

Arjmandi BH, Khalil DA, Smith BJ, Lucas EA, Juma S, Payton ME, Wild RA 2003. Soy protein has a greater effect on bone in postmenopausal women not on hormone replacement therapy, as evidenced by reducing bone resorption and urinary calcium excretion. $J$ Clin Endocr Metab 88: 1048-1054.

Baber R 2010. Phytoestrogens and post reproductive health. Maturitas 66: 344-349.

Beck V, Rohr U, Jungbauer A 2005. Phytoestrogens derived from red clover: An alternative to estrogen replacement therapy? J Steroid Biochem 94: 499-518.

Beach KH, Smith RR 1979. Plant regeneration from callus of red and crimson clover. Plant Sci Lett 16: 231-237.

Brzezinski A, Debi A 1999. Phytoestrogens: the "natural", selective estrogen receptor modulators? Eur J Obstet Gyn R B 85: 47-51.

Cesar IC, Braga FC, Soares CDV, Nunan EA, Pianetti GA, Condessa FA, Barbosa A, Campos LMM 2006. Development and validation of a RP-HPLC method for quantification of isoflavone aglycones in hydrolyzed soy dry extracts. $J$ Chromatogr $B$ 836: 74-78.

Colgecen H, Toker MC 2008. Plant regeneration of natural tetraploid Trifolium pratense L. Biol Res 41: 25-31.

Cornwell T, Cohick W, Raskin I 2004. Dietary phytoestrogens and health. Phytochemistry 65: 995-1016.

Davis SR 2001. Phytoestrogen therapy for menopausal symptoms? Brit Med J 323: 354-355.

Delmonte P, Perry J, Rader JI 2006. Determination of isoflavones in dietary supplements containing soy, Red Clover and Kudzu: Extraction followed by basic or acid hydrolysis. J Chromatogr A 1107: 59-69.

Dixon RA (2004). Phytoestrogens. Annu Rev Plant Biol 55: 225-261.

Djuric Z, Chen G, Doerge DR 2001. Effects of soy isoflavone supplementation on markers of oxidative stres in men and women. Cancer Lett 172: 1-6.

Duncan DB 1955. Multiple range and multiple F-test. Biometrics 11: 1-42.

Elci S. 1982. The utilization of genetic resource in fodder crop breeding, eucarpia. In: Fodder Crop Section, 1316 September, Aberystwyth, UK.

Gamborg OL, Murashige T, Thorpe TA, Vasil IK. 1976. Plant tissue culture media. In vitro 12: 473-478.

Ganry O 2002. Phytoestrogen and breast cancer prevention. Eur J Cancer Prev 11: 519-522.

Geller SE, Studee L 2006. Soy and red clover for mid-life and aging. Climacteric 9: 245-263.

Howes LG, Howes JB, Knight DC 2006. Isoflavone therapy for menopausal flushes: A systematic review and meta-analysis. Maturitas 55: 203-211.

Jiang B, Kronenberg F, Balick MJ, Kennelly EJ 2006. Analysis of formononetin from black cohosh (Actaea racemosa). Phytomedicine 13: 477-486.

Kasparova M, Siatka T, Spilkova J, Dusek J 2006. Explant culture of Trifolium pratense L. Ceska Slov Farm 55: 44-47.

Kennely E, Baggett S, Nuntanakorn P, Ososki A, Mori S 2002. Analysis of thirteen populations of black cohosh for formononetin. Phytomedicine 9: 461-467.

Kledjus B, Vitamvasova-Sterbova D, Kuban V 2001. Identification of isoflavone in red clover (T. pratense L.) by liquid chromatography-mass spectrometry after two-dimensional solid-phase extraction. Anal Chim Acta 450: 81-97.

Klejdus B, Mikelova R, Adam V, Zehnalek J, Vacek J, Kizek R, Kuban V 2004. Liquid chromatographic- mass spectrometric determination of genistin and daidzin in soybean food samples after accelerated solvent extraction with modified content of extraction cell. Anal Chim Acta 517: 1-11.

Klejdus B, Mikelova R, Petrlova J, Potesil D, Adam V, Stiborova M, Hodek P, Vacek J, Kizek R, Kuban V 2005. Determination of isoflavones in soy bits by fast column high-performance liquid chromatography coupled with UV-visible diode-array detection. $J$ Chromatogr A 1084: 71-79.

Kledjus B, Vacek J, Lojkova L, Benesova L, Kuban V 2008. Ultrahigh-pressure liquid chromatography of isoflavones and phenolic acids on different stationary 
phases. J Chromatogr A 1195: 52-59.

Krenn L, Unterrieder I, Ruprechter R 2002. Quantification of isoflavones in red clover by high-performance liquid chromatography. J Chromatogr B 777: 123-128.

Lissin LW, Cooke JP 2000. Phytoestrogens and cardiovascular health? J Am Coll Cardiol 35: 1403-1410.

Lu W, Anderson KE, Grandy JJ 2001. Effects of an isoflavonefree soy diet on ovarian hormones in premenopausal women. J Clin Endocr Metab 86: 3045-3052.

Luczkiewicz M, Glod D 2003. Callus cultures of Genista plants-in vitro material producing high amounts of isoflavones of phytoestrogenic activity. Plant Sci 165: 1101-1108.

Magee PJ, Rowland IR 2004. Phyto-oestrogens, their mechanism of action: current evidence for a role in breast and prostate cancer. Brit J Nutr 91: 513-531.

Matkowski A 2004. Isoflavonoid production in callus from different organs of (Wild.) Ohwi. J Plant Physiol 161: 343-346.

Mishra SI, Dickerson V, Najm W 2003. Phytoestrogens and breast cancer prevention: what is the evidence? $\mathrm{Am} \mathrm{J}$ Obstet Gynecol 188: 66-70.

Murashige T, Skoog F 1962. A revised medium for rapid growth and bio assays with tobacco tissue cultures. Physiol Plantarum 15: 473-497.

Phillps GC, Collins GB 1979. In vitro tissue culture of selected legumes and plant regeneration from callus cultures of red clover. Crop Sci 19: 59-64.

Pinar M, Buyukkartal HN, Colgecen H 2001. Pollen and seed morphology of diploids and natural tetraploids of Trifolium pratense L. (Leguminosae). Acta Biol Cracov Bot 43: 27-32.

Ramos GP, Apel MA, Morais CB, Ceolato PC, Schapoval
EES, Agnol MD, Zuanazzi JAS. 2011. In vivo and in vitro anti-inflammatory activity of red clover Trifolium pratense dry extract. Rev Bras Farmacogn 22: 176-180.

Smiley DA, Khalil RA 2009. Estrogenic compounds, estrogen reseptors and vascular cell signaling in the aging blood vessels. Curr Med Chem 16: 1863-1887.

van de Weijer PHM, Barentsen R 2002. Isoflavones from red clover (Promensil) significantly reduce menopausal hot flush symptoms compared with placebo. Maturitas 42: 187-193.

Wang H, Holl FB 1988. In vitro culture and the incidence of somaclonal variation in regenerated plants of Trifolium pratense L. Plant Sci 55: 159-167.

Wang CC, Prasain JK, Barnes S 2002. Review of the methods used in the determination of phytoestrogens. $J$ Chromatogr B 777: 3-28.

Wu Q, Wang M, Simon JE 2003. Determination of isoflavones in red clover and related species by high-performance liquid chromatography combined with ultraviolet and mass spectrometric detection. J Chromatogr A 1016: 195-209.

\section{*Correspondence}

\section{Hatice Çölgeçen}

Zonguldak Karaelmas University, Faculty of Arts and Sciences, Department of Biology

67100 İncivez, Zonguldak, Turkey

colgecen@karaelmas.edu.tr

Tel.: +9037225740101128

GSM: +90 5379794047

Fax: +90 3722574181 